\title{
Control of DFIG Wind Turbines Based on Indirect Matrix Converters in Short Circuit Mode to Improve the LVRT Capability
}

\author{
Ahmad Khajeh and Reza Ghazi \\ Electrical Engineering Department, Faculty of Engineering, Ferdowsi University of Mashhad, P.O. Box 9177948974, Mashhad, Iran \\ Correspondence should be addressed to Ahmad Khajeh; ahmad_khajeh79@yahoo.com
}

Received 29 August 2013; Revised 8 October 2013; Accepted 9 October 2013

Academic Editor: C. M. Liaw

Copyright (C) 2013 A. Khajeh and R. Ghazi. This is an open access article distributed under the Creative Commons Attribution License, which permits unrestricted use, distribution, and reproduction in any medium, provided the original work is properly cited.

\begin{abstract}
Nowadays, the doubly-fed induction generators (DFIGs) based wind turbines (WTs) are the dominant type of WTs. Traditionally, the back-to-back converters are used to excite the rotor circuit of DFIG. In this paper, an indirect matrix converter (IMC) is proposed to control the generator. Compared with back-to-back converters, IMCs have numerous advantages such as higher level of robustness, reliability, and reduced size and weight due to the absence of bulky electrolytic capacitor. According to the recent grid codes wind turbines must have low voltage ride-through (LVRT) capability. In this paper a new crowbar system is proposed so that along with the control system it protects the IMC from large fault currents and supports the grid voltage dips during grid faults. This crowbar system is provided using the existing converter switches to establish a short circuit mode without any extra circuitry. Even in severe fault conditions, the duration of short circuit mode is quite small so the control system will be activated shortly after the fault to inject reactive power as required by new LVRT standards. Therefore, the new LVRT standards are well satisfied without any extra costs. PSIM simulation results confirm the efficiency of the proposed method.
\end{abstract}

\section{Introduction}

Wind energy has been found as the fastest growing renewable power generation resources over the world. Government support and advancement in technology of WT have accelerated this rapid growth. Based on estimation the wind power capacity becomes double every three years [1].

Due to their superior characteristics, most of the gridconnected WTs operate at a variable speed. Among the different variable speed types, the DFIG is the most promising one. The stator winding of DFIG is directly connected to the grid, while the rotor winding is connected to the grid through an ac-ac power electronic converter having bidirectional switches. Traditionally the back-to-back converters are used to excite the rotors of DFIGs. The presence of the dclink capacitor in this arrangement is a serious drawback as it increases the costs and reduces the overall lifetime of the system and also makes the system bulky [2].
In this paper, the back-to-back converter arrangement is replaced by an indirect matrix converter (IMC) to control the generator as shown in Figure 1. The main advantages of a matrix converter are robustness, reliability with less size and weight due to the absence of the bulky electrolytic capacitor, controllable input power factor, nearly sinusoidal input current, and output voltage with only switching frequency harmonics, along with bidirectional power flow. The direct matrix converter (DMC) encounters the commutation problems requiring a complex control circuitry. While in IMC all switches at the line side will turn on and off at zero current, so the commutation problems are eliminated [3]. Therefore, the IMCs are the most promising devices for wind energy applications regarding their robustness, reliability, and reduced size.

In the past, based on most grid codes, wind turbines were allowed to be disconnected from the grid during the grid disturbances and the abnormal voltage reduction. With the 


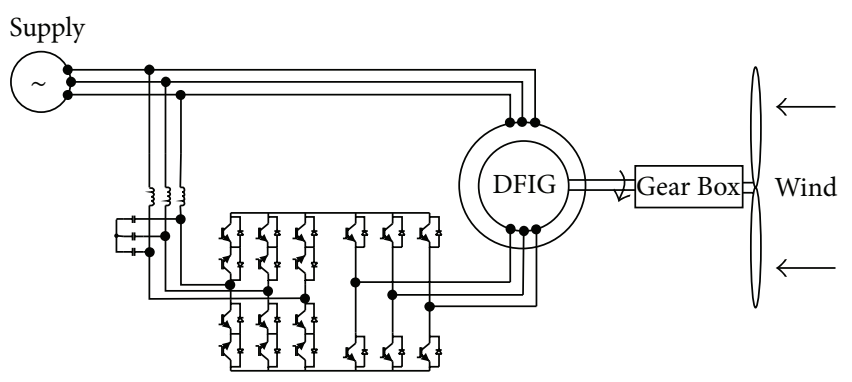

FIgURE 1: Wind Turbine based on the DFIG excited by indirect matrix converter.

increased capacity of wind powers in the power systems over the years, the sudden loss of wind turbines during the grid faults resulting from turbines disconnection could generate control problems of frequency and voltage in the system so leading to the voltage collapse in worst cases. The increased penetration of wind energy into the power system over the last decade has therefore led to a serious concern about its influence on the dynamic behavior of the power system. To handle this issue the grid codes are revised by system operators in several countries [4]. According to the new grid codes the wind turbines must be remain connected to the network on the occurrence of grid faults and tolerate the resulting voltage drops. This feature is known as the low voltage ride-through (LVRT) capability of a power plant. The LVRT requirement defines a specific voltage profile with limiting curves depending on the grid voltage dip depth. Moreover, in some grid codes such as Germany, wind turbines should also inject reactive power to help the grid voltage recovery.

Because of direct connection of stator winding to the grid and the small rating of power electronic converter in the rotor side, DFIG based wind turbine is very sensitive to grid disturbances, especially to voltage dips during grid faults. Grid faults, even those occurring far from the wind turbines, can cause voltage drops at the point of wind turbine connection. The abrupt drop of the grid voltage will make an increase in the current of stator windings of the DFIG. Because of the magnetic coupling between stator and rotor, this current will also flow in the rotor circuit and the power converter. At present, the back-to-back converter is the most frequently used power electronic converter in the wind turbines industry. Therefore, the most of research works have been done to enhance the LVRT ability of DFIG utilizing this type of converters. So the grid faults cause over current in the rotor windings and over voltage in the dc-link capacitor; hence, the proper protection should be provided to safekeep the converter. Various solutions have been proposed to solve the problem. Some of them are briefly reviewed as follows.

The most popular and reliable method is based on the use of a protective circuit known as crowbar. The crowbar consists of resistors connected to the rotor windings by means of electronic switches. In active crowbar the switches are controllable such as IGBTs whereas in passive one they are antiparallel thyristors. The active crowbar allows opening the circuit when the currents reach safe region. The passive crowbar allows closing the circuit but not opening it until the crowbar currents reach zero. Therefore, according to the new grid codes, the passive crowbar is not appropriate for the modern wind turbines. When a fault occurs, the rotor windings get connected to the crowbar while the converter is tripped. Several papers have discussed the implementation and control of crowbar [5-12]. Different types of crowbars realization are shown in Figure 2. The crowbar can effectively protect the rotor converter under serious grid faults. But its main drawback is that, when the crowbar is activated, the rotor converter cannot control the active and reactive power during crowbar activation, so the DFIG operates as a cage induction generator, absorbing extra reactive power from the grid and deteriorates the grid voltage profile.

Another approach is to modify the rotor-side converter control system to limit the fault currents without using any extra hardware circuit [13-21]. In this method at serious grid faults, the required voltage in the rotor-side converter becomes too large and exceeds its voltage capability. Therefore, the rotor current greatly increases thus leading to converter destruction. This method is beneficial as it does not require any additional hardware but it is suitable for moderate faults.

Another solution for LVRT is to use an additional energy storage system (ESS) connected to the dc link [22-26]. The ESS can balance the extra power that goes through the rotor circuit during a grid fault transient, but it also requires a rotor side converter with higher current ratings having extra cost and more system complexity.

Utilizing matrix converters in DFIG wind turbines is still in research phase. Most of the works have dealt with their normal operation [27-30]. The control of a DFIG using an indirect matrix converter for dynamic performance evaluation under normal grid condition is presented in [27]. Sigmadelta modulator to control IMC switches of DFIG based WT is proposed in [28]. By using this modulation method, torque pulsations and harmonic content of currents are reduced. Therefore, the power quality of WT is improved. The capability of the input converter to generate different virtual dc-link voltage levels is also proposed in [29]. This method reduces both the commutation losses of output converter and common mode voltage. Due to small voltage required around the synchronous speed, this strategy is suitable in DFIG applications.

Dynamic performance of DFIG using two-stage IMC under voltage dip condition has been discussed in [30] without providing any protection. As simulation results show for $80 \%$ terminal voltage sag, the stator current reaches $2.5 \mathrm{pu}$. Without any protection method, this high current could damage the IGBT switches of the IMC. According to new LVRT standards, the reactive power injection to the grid is mandatory to improve the voltage recovery. Results of [30] indicate that, during the fault, about $0.7 \mathrm{pu}$ reactive power is absorbed from the grid which makes the voltage deeper. Therefore, the existing controller which is designed for normal operating condition is ineffective during fault conditions.

To solve these drawbacks and satisfy the new LVRT standards, in present paper a new method is proposed to protect the IMC with DFIG following the grid faults. In this method a new short circuit mode is proposed to control 


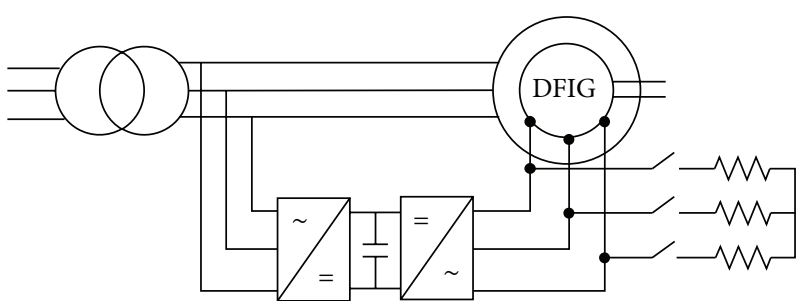

(a)

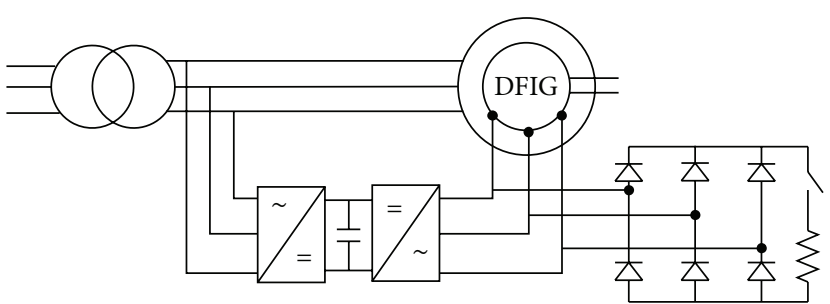

(b)

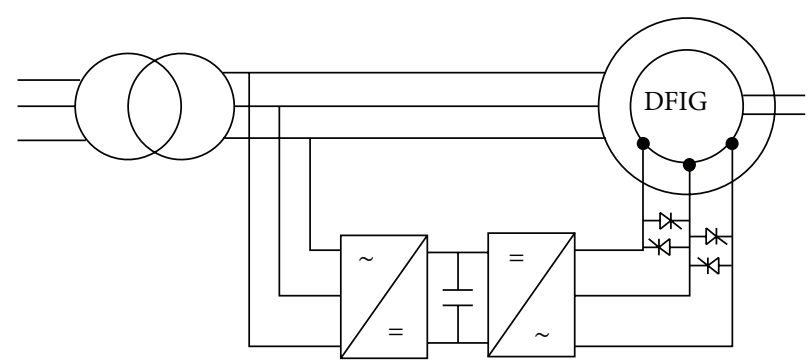

(c)

FIGURE 2: Different types of crowbar realization.

the short circuit currents of the DFIG wind turbines based on IMC. In addition to protect the IMC against large fault currents, the proposed method also makes it possible to inject reactive power during grid faults to improve voltage recovery, so the new LVRT standards are well satisfied. The PSIM simulation results confirm the efficiency of the proposed method.

This paper is organized as follows. In Section 2, LVRT requirement of a German transmission system operator is discussed. Modeling and control of the DFIG based wind turbine is presented in Section 3. The vector control of the DFIG is briefly discussed in Section 4. In Section 5, the proposed method is presented and analyzed. The simulation results are provided in Section 6. Finally, Section 7 concludes the paper.

\section{LVRT Requirement}

The German transmission system operator E.ON Netz was the first power system operator, which introduced grid codes for wind turbines and is followed now by many other network operators in several countries. E.ON introduces a voltage profile and the limiting curves and regions defining the LVRT requirement as shown in Figure 3. Accordingly, wind turbines must stay connected even when the voltage at the point of common coupling (PCC) drops to zero. The $150 \mathrm{~ms}$ delay shown in Figure 3 accounts for the normal operating time of protection relays. Three-phase short circuits or faultrelated symmetrical voltage dips must not lead to instability above the limit line 1 in Figure 3 or disconnection of the wind turbines from the grid. Within the shaded area and above limit line 2 in Figure 3, LVRT is also required but in case of instability a short term interruption (STI) is allowed. Below the limit line 2 in Figure 3, no LVRT is required and STI from the grid is always permissible. Here, resynchronization times of more than 2 seconds and an active power increase

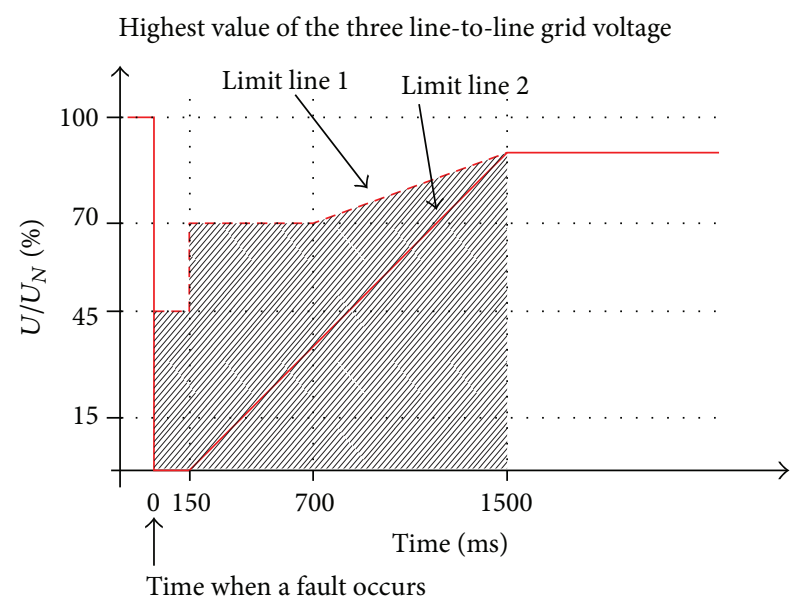

FIGURE 3: E.ON Netz LVRT requirement.

following fault clearance of less than $10 \%$ of the rated power per second are also possible. According to the E.ON Netz grid code, wind turbines have to provide a mandatory voltage support during voltage dips. Wind turbines have to supply $1 \mathrm{pu}$ reactive current when the voltage falls below $0.5 \mathrm{pu}$.

\section{Modeling and Control of DFIG Based Wind Turbine}

In this section, dynamic model of DFIG based wind turbine is provided. The stator winding of DFIG is directly connected to the grid, and the rotor winding is coupled via an IMC. The IMC must handle the slip power, that is, about $30 \%$ of the rated power of wind turbine. The speed range of the generator is typically $\pm 30 \%$ of synchronous speed, thus providing flexibility to operate in both sub- and supersynchronous modes, depending on the wind conditions. The inverter of the IMC 
is used to control the active and reactive power of the DFIG. The rectifier of the IMC is often operated at unity power factor. Depending on the rotor speed, the IMC will either absorb power (subsynchronous) from grid or inject power (supersynchronous) to the grid. Therefore, the IMC must have the ability of bidirectional power flow to the network.

3.1. Turbine Model. The mechanical power extracted by a wind turbine from the wind is expressed by

$$
P=\frac{1}{2} A \cdot \rho \cdot C_{p}(\lambda, \beta) \cdot v_{\omega}^{3},
$$

where $A$ is the area covered by the rotor blades, $\rho$ is the air density, $C_{p}$ is the power coefficient, representing the amount of power the turbine can extract, and $v_{\omega}$ is the wind speed. The power available in the wind cannot be extracted completely. Theoretically the maximum captured power is $59 \%$ of the power available in the wind. The power coefficient is a function of the tip-speed ratio $\lambda$ and the pitch angle of the rotor blades $\beta$. The tip-speed ratio is defined by

$$
\lambda=\frac{R \Omega_{t}}{v_{\omega}},
$$

where $R$ is the radius of the rotor blades and $\Omega_{t}$ is the angular speed of the blades. For each pitch angle of the rotor blades, there is an optimum tip-speed ratio $\lambda_{\text {opt }}$ for which $C_{p}\left(\lambda_{\text {opt }}, \beta\right)$ takes a maximum value. Therefore, for wind speeds below rated value, the existing power is below the rated power, so power coefficient is optimized by adjusting the tip-speed ratio to achieve the maximum power coefficient. The pitch angle is kept constant in this region which is called the maximum power point tracking (MPPT) of wind turbines. On contrary, at wind speeds above rated value the extracted wind power has to be limited by means of blade pitching. In this paper the MPPT is accomplished through a look-up table. The MPPT table ensures the plant operation at maximum power for partial loads and specifies that the rated speed is achieved at rated power. According to [4] coordination between the control of the mechanical and the electrical system exists.

3.2. DFIG Model. For DFIG modeling a fifth-order dynamic model of the DFIG is used in this paper [31]. The model in a two-axis $d$ - $q$ synchronous reference frame is given by

$$
\begin{gathered}
v_{s d q}=R_{s} i_{s d q}+\frac{d \psi_{s d q}}{d t}+j \omega_{s} \psi_{s d q}, \\
v_{r d q}=R_{r} i_{r d q}+\frac{d \psi_{r d q}}{d t}+j\left(\omega_{s}-\omega_{r}\right) \psi_{r d q}, \\
T_{e m}=\frac{p}{2}\left(\psi_{r q} i_{r d}-\psi_{r d} i_{r q}\right) \\
\psi_{s d q}=L_{s} i_{s d q}+L_{m} i_{r d q}, \\
\psi_{r d q}=L_{m} i_{s d q}+L_{r} i_{r d q}, \\
L_{s}=L_{l s}+L_{m}, \\
L_{r}=L_{l r}+L_{m} .
\end{gathered}
$$

In these equations, $R_{s}, R_{r}, L_{s}, L_{r}, L_{l s}$, and $L_{l r}$ are the resistors and inductors of the stator and rotor windings, $L_{m}$ is the magnetizing inductance, $v_{s d q}, v_{r d q}, i_{s d q}, i_{r d q}, \psi_{s d q}$, and $\psi_{r d q}$ are the space vectors of the stator and rotor voltages, currents, and fluxes, respectively, $\omega_{s}$ is the synchronous speed of the generator, $\omega_{r}$ is the electrical speed of the rotor, and $p$ is the number of poles.

3.3. Indirect Matrix Converter. Due to the numerous advantages of matrix converters over back-to-back converters, in this paper the IMC is used to control the DFIG. An IMC consists of a rectification part on the input side and an inversion part on the output side, connected via fictitious dc link as shown in Figure 4. For purposes of analysis, we can assume that the switching frequency is far greater than the fundamental frequency of both the input voltage and output current. Thus during each switching cycle, it is assumed that both input voltage and output current are constant.

The rectifier has six bidirectional switches with the ability of conducting current and blocking voltage in both directions. The rectifier side objective is to achieve maximum positive voltages at the fictitious dc-link and sinusoidal input currents. Usually the grid side converter of DFIG exchanges zero reactive power at the grid point. In order to obtain maximum dc-link voltage, the input phase voltage which has the highest absolute value is connected to the positive or negative rail of the dc link at 60 degree intervals depending on its polarity. To achieve sinusoidal current and unity power factor at the input side, regardless of the load type, the other two phase voltages are modulated so that the reference current space vector be in phase with the voltage space vector. Space vectors of the input current are shown in Figure 5. Assume the input voltages are

$$
\begin{aligned}
& v_{a}=V_{m} \cos \theta_{a}=V_{m} \cos \left(\omega_{i} t\right), \\
& v_{b}=V_{m} \cos \theta_{b}=V_{m} \cos \left(\omega_{i} t-\frac{2 \pi}{3}\right), \\
& v_{c}=V_{m} \cos \theta_{c}=V_{m} \cos \left(\omega_{i} t+\frac{2 \pi}{3}\right),
\end{aligned}
$$

where $V_{m}$ is the maximum of the input phase voltage and $\omega_{i}$ is the angular frequency. In order to achieve unity power factor at the input side, the input currents must be in phase with the input voltages. Therefore, input currents are as follows:

$$
\begin{aligned}
& I_{a}=I_{m} \cos \left(\omega_{i} t\right), \\
& I_{b}=I_{m} \cos \left(\omega_{i} t-\frac{2 \pi}{3}\right), \\
& I_{c}=I_{m} \cos \left(\omega_{i} t+\frac{2 \pi}{3}\right),
\end{aligned}
$$

where $I_{m}$ is the maximum of the input current. On the rectifier side always two switches, one from top and another from the bottom, are $\mathrm{ON}$ and the others are OFF.

To calculate the duty cycle of each switch, first the angle of the input voltage space vector is obtained. This is the reference angle of the current space vector to obtain the unity 


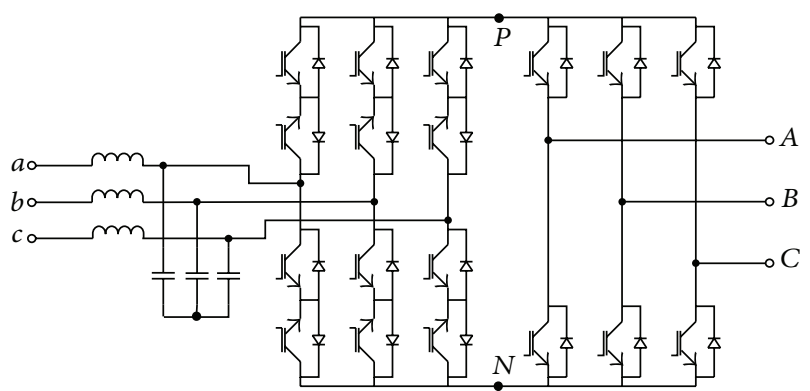

FIGURE 4: Indirect matrix converter topology.

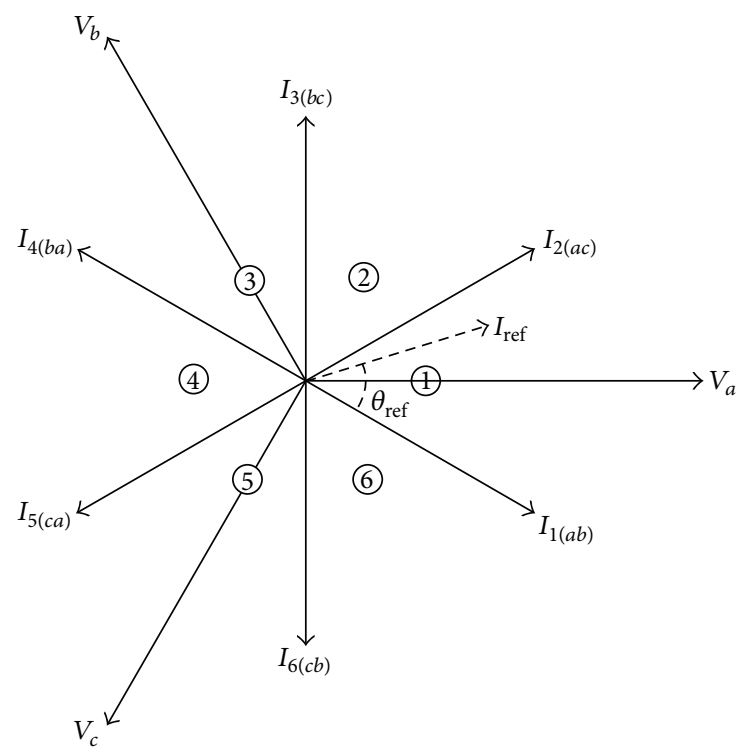

FIGURE 5: Space vectors of the input current.

power factor. Regarding the angle of current space vector, its corresponding sector is determined from Figure 5. Then the current reference vector can be built using two adjacent vectors of each section. For example, when the reference current space vector is located in the first section, two adjacent vectors are " $a b$ " and " $a c$." In this section, voltage of phase " $a$ " has the highest absolute value. Therefore, in 60 degree duration of this section, the top switch of phase " $a$ " is ON and the bottom switches of phases " $b$ " and " $c$ " get modulated. Vector " $a b$ " means that the top switch of phase " $a$ " and the bottom switch of phase " $b$ " are ON, and " $a c$ " means that the top switch of phase " $a$ " and the bottom switch of phase " $c$ " are ON and so on.

So in one period of switching frequency in this section, input currents are as follows:

$$
i_{a}=\left(d_{a b}+d_{a c}\right) i_{d c}, \quad i_{b}=-d_{a b} i_{d c}, \quad i_{c}=-d_{a c} i_{d c},
$$

where $d_{a b}$ and $d_{a c}$ are the duty cycles of $I_{1(a b)}$ and $I_{2(a c)}$, respectively, and $i_{d c}$ is the dc-link current. As only the active vectors are used, the following relationships hold:

$$
d_{a b}+d_{a c}=1 \Longrightarrow i_{a}=i_{d c} \text {. }
$$

Therefore, the duty cycles of active vectors in section one are given by

$$
d_{a b}=-\frac{i_{b}}{i_{a}}, \quad d_{a c}=-\frac{i_{c}}{i_{a}} .
$$

The duty cycles in the other sections are obtained similarly. Based on this modulation method in the rectifier stage, the average fictitious dc-link voltage in each period is

$$
\begin{gathered}
V_{d c}=\frac{3 \cdot V_{m}}{2 \cdot\left|\cos \left(\theta_{\text {in }}\right)\right|}, \\
\left|\cos \left(\theta_{\text {in }}\right)\right|=\max \left(\left|\cos \left(\theta_{a}\right)\right|,\left|\cos \left(\theta_{b}\right)\right|,\left|\cos \left(\theta_{c}\right)\right|\right),
\end{gathered}
$$

where $\theta_{\text {in }}$ is the angle of the input voltage space vector. On the output stage, the space vector modulation (SVM) is used to generate the required rotor voltage space vector by currents controllers. Inverter voltage space vectors along with the reference vector are shown in Figure 6.

Duty cycles of active vectors on the inverter stage are as follows:

$$
d_{\alpha}=k \cdot \sin \left(60^{\circ}-\theta_{i}\right), \quad d_{\beta}=k \cdot \sin \left(\theta_{i}\right),
$$

where $k$ is the modulation index and is given by

$$
k=\frac{2 \cdot\left|\cos \left(\theta_{\text {in }}\right)\right| \cdot \widehat{V}_{r}}{\sqrt{3} \cdot V_{m}},
$$

where $V_{r}$ is the absolute of the reference voltage. Considering modulation of both the input and output sides, the final duty cycles of active vectors are

$$
\begin{array}{ll}
d_{\alpha \gamma}=d_{\gamma} \cdot d_{\alpha}, & d_{\beta \gamma}=d_{\gamma} \cdot d_{\beta}, \\
d_{\alpha \delta}=d_{\delta} \cdot d_{\alpha}, & d_{\beta \delta}=d_{\delta} \cdot d_{\beta},
\end{array}
$$

where $d_{\gamma}$ is the first vector of the rectifier section and $d_{\delta}$ is the second vector of the rectifier section. Finally, the duty cycles of the zero vectors are calculated as

$$
\begin{aligned}
& d_{0}=1-\left(d_{\gamma}+d_{\delta}\right) \cdot\left(d_{\alpha}+d_{\beta}\right), \\
& d_{0 \gamma}=\frac{d_{\gamma}}{\left(d_{\gamma}+d_{\delta}\right)} d_{0}, \quad d_{0 \delta}=\frac{d_{\delta}}{\left(d_{\gamma}+d_{\delta}\right)} d_{0} .
\end{aligned}
$$

The overall switching scheme in one period is depicted in Figure 7. Fictitious dc-link voltage for simulated IMC is shown in Figure 8.

\section{Vector Control of DFIG}

The goal of the DFIG controller is the independent control of the stator active and reactive power. The active power reference is determined by MPPT algorithm and the reactive power is set in order to achieve the desired power factor. Stator flux $d-q$ reference frame is the most widely used DFIG vector control in the wind turbine applications. Thus, the inverter of IMC is controlled in a stator flux $d-q$ reference 


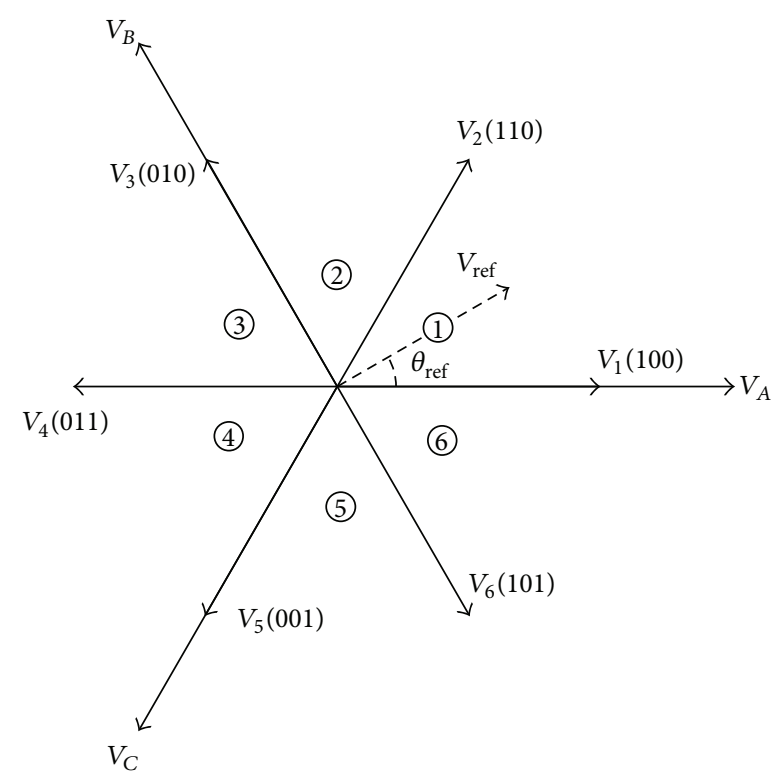

FIgURE 6: Space vectors of the output voltage.

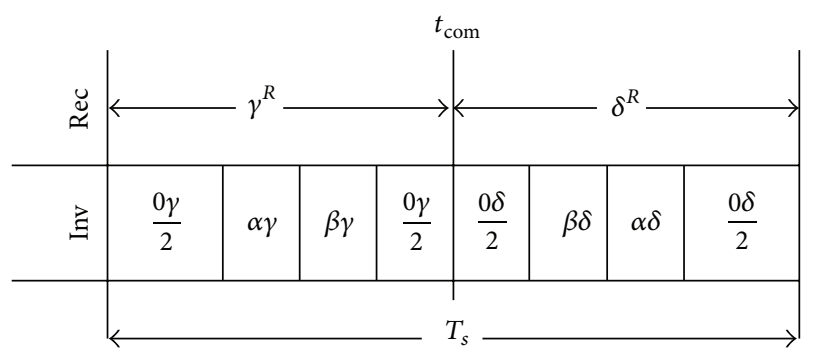

FIGURE 7: Switching scheme in one period.

frame, with the $d$-axis oriented along the stator flux vector position. For this reference frame selection, the DFIG model can be written as

$$
\psi_{s}=\psi_{s d}, \quad 0=\psi_{s q} .
$$

Substituting (15) into (4), we obtain

$$
i_{d s}=\frac{1}{L_{s}}\left(\psi_{s}-L_{m} i_{d r}\right), \quad i_{q s}=-\frac{L_{m}}{L_{s}} i_{q r}
$$

$\psi_{d r}=\sigma L_{r} i_{d r}+\frac{L_{m}}{L_{s}} \psi_{s}, \quad \psi_{q r}=\sigma L_{r} i_{q r}, \quad \sigma=1-\frac{L_{m}^{2}}{L_{s} L_{r}}$,

where $\sigma$ is the leakage factor. In DFIG, the rotor voltages are control variables which control the rotor currents. Substituting (16) into (3), rotor voltages can be written as

$$
\begin{aligned}
& v_{d r}=R_{r} i_{d r}+\frac{d}{d t}\left(\sigma L_{r} i_{d r}+\frac{L_{m}}{L_{s}} \psi_{s}\right)-\left(\omega_{s}-\omega_{r}\right)\left(\sigma L_{r} i_{q r}\right), \\
& v_{q r}=R_{r} i_{q r}+\frac{d}{d t}\left(\sigma L_{r} i_{q r}\right)+\left(\omega_{s}-\omega_{r}\right)\left(\sigma L_{r} i_{d r}+\frac{L_{m}}{L_{s}} \psi_{s}\right) .
\end{aligned}
$$

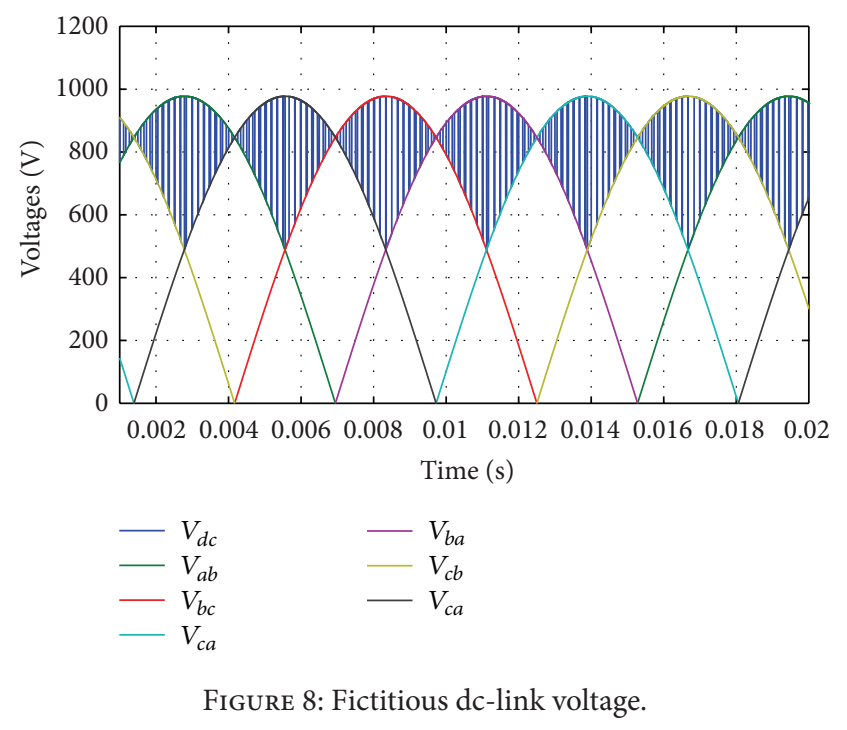

In dynamic performance analysis of the overall system, cross-coupling terms in (17) are added to control loops as feed-forward compensation terms. The stator active and reactive power can be calculated as

$$
P_{s}=\frac{3}{2}\left(v_{d s} i_{d s}+v_{q s} i_{q s}\right), \quad Q_{s}=\frac{3}{2}\left(v_{q s} i_{d s}-v_{d s} i_{q s}\right) .
$$

In steady state, the stator flux is proportional to the grid voltage. Neglecting the small voltage drop in the stator resistance yields

$$
V_{s}=v_{q s}, \quad 0=v_{d s}, \quad\left|V_{s}\right| \simeq \omega_{s}\left|\psi_{s}\right| .
$$

Thus, when orienting the $d$-axis with the stator flux, the voltage aligns with the $q$-axis. Combining (19) and (16) with (18), we obtain

$$
\begin{gathered}
P_{s}=\frac{3}{2} v_{d s} i_{d s}=-\frac{3}{2} V_{s} \frac{L_{m}}{L_{s}} i_{q r} \\
Q_{s}=\frac{3}{2} v_{q s} i_{d s}=\frac{3 V_{s}}{2 L_{s}}\left(\psi_{s}-L_{m} i_{d r}\right) .
\end{gathered}
$$

The above equations clearly show that, under the stator flux orientation, the active and reactive powers are decoupled and can be controlled via the rotor currents. By means of $i_{q r}$, we can control the active power while the reactive power can be controlled via the $i_{d r}$. Using the above equations, the reference currents can be calculated from the desired powers. The schematic diagram of stator flux based vector control of DFIG along with MPPT algorithm is shown in Figure 9.

\section{New LVRT Scheme Based on the Short Circuit Mode}

5.1. Operation and Implementation. In wind turbines based on back-to-back converters, using the crowbar is the most 


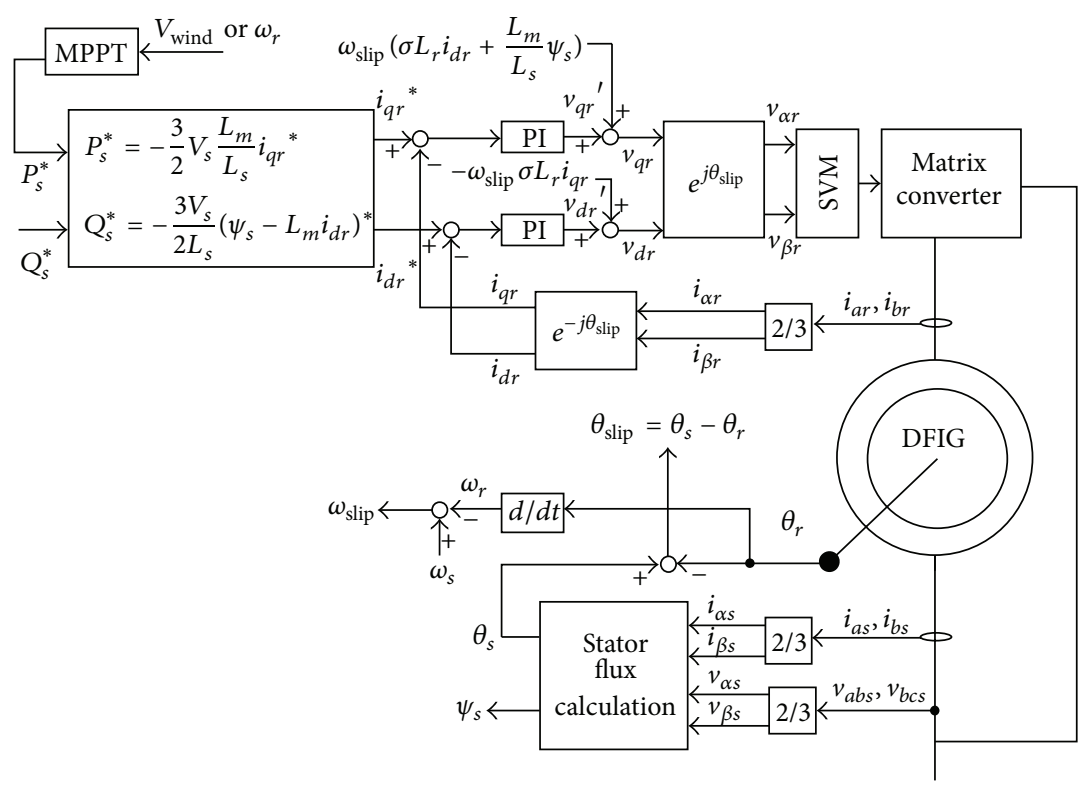

FIGURE 9: Schematic diagram of vector control of DFIG.

popular and reliable scheme to relieve the problems of over current in rotor windings and over voltage at dc link. As shown in Figure 2, these schemes employ extra circuitry to do the job. However, in patent [32] for back-to-back converter a scheme is presented using only the existing converter switches. In this scheme the crowbar function is performed by handling the fault currents through applying zero vectors by inverter part of the converter. Simultaneous zero vectors are achieved by means of turning on 3 upper switches or lower switches. Here due to the presence of dc-link capacitor turning on both switches of a leg is prohibited to prevent it from short circuit.

In the present paper based on this concept a new crowbar scheme is proposed and applied on DFIG excited by an indirect matrix converter (Figure 10). In the indirect matrix converter due to the absence of dc-link capacitor, the limitation of simultaneous switching of two switches of each leg is removed. Therefore, in the occurrence of large voltage dips all output stage switches of IMC are turned on and those of input stage are turned off simultaneously. This mode is known as short circuit mode and could do the crowbar task. Therefore, a new low-cost crowbar is realized that does not require any additional hardware. Activation of the short circuit mode is based on the output of a comparator. The comparator block compares the maximum absolute value of the rotor currents with a threshold value. If the output of the comparator is zero, then the gate pulses generated by SVM modulator will apply to the IMC. In case of occurring faults, the rotor currents will exceed the threshold value and comparator output value will change to one. Hence, the controller switches to the short circuit mode and apply the new crowbar. Furthermore, in IMC there are six switches in this mode (Figure 10). So, each switch in this scheme should tolerate half the current of backto-back converter case. Therefore, it can work well in DFIG based on IMC even for severe faults.
5.2. Dynamic Performance. The dynamic performance of the proposed scheme is investigated during the paper. Theoretical analysis of the dynamic behavior of the DFIG during threephase voltage dips has been investigated in previous works, especially in $[14,15]$. Both of them proposed inserting extra resistances in stator circuit along with control modification to improve the behavior of the DFIG. During faults the proposed method could be considered as a crowbar having a small resistance. In normal operating condition, the space vector of the stator flux in DFIG rotates at synchronous speed. Referenced to rotor, it rotates at the slip speed and induces small voltages in it. Due to continuity principle of the stator flux, when the DFIG experiences a voltage dip, the stator flux encompasses two components: an ac component corresponds to the remaining voltage of the DFIG terminal and a dc component to maintain flux continuity. The dc component is fixed to the stator, but it is seen by the rotor as a flux that rotates at the rotor speed. Note that the rotor speed is significantly greater than the slip speed and so the induced voltages in rotor are much greater. Therefore, it is desired to increase the damping of the dc term to improve transient performance of the DFIG. Impact of the proposed method on the stator flux dynamic is investigated to compare with disconnecting the converter as follows.

If the converter is disconnected from the rotor, the dynamic equation of the stator flux based on (3) and (4) can be calculated by

$$
i_{s d q}=\frac{\psi_{s d q}}{L_{s}} \Longrightarrow \frac{d \psi_{s d q}}{d t}=-\frac{R_{s}}{L_{s}} \psi_{s d q}-j \omega_{s} \psi_{s d q}+v_{s d q} .
$$

The pole of the above equation is $s=-R_{s} / L_{s}-j \omega_{s}$. The damping coefficient of this pole is $\alpha=-R_{s} / L_{s}$ and is equal to -0.38 for the studied DFIG. Therefore, the pole is close to imaginary axis with poor damping. The dynamic equation of 


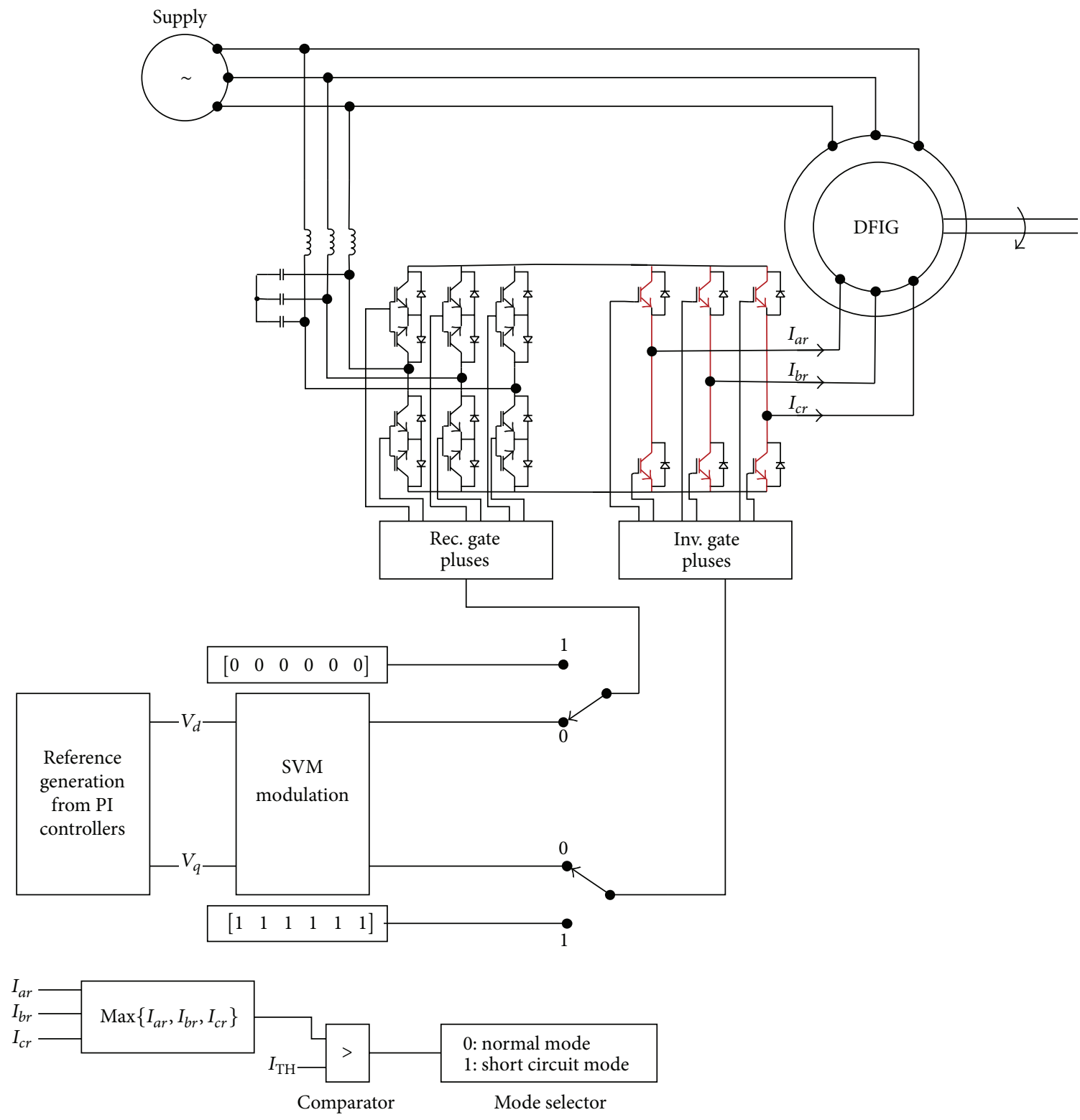

FiguRE 10: New crowbar structure.

the stator flux in case of applying the proposed method will change to

$$
\begin{aligned}
i_{s d q} & =\frac{L_{r} \psi_{s d q}-L_{m} \psi_{r d q}}{L_{s} L_{r}-L_{m}^{2}} \Longrightarrow \frac{d \psi_{s d q}}{d t} \\
& =-\frac{R_{s}}{\sigma L_{s}} \psi_{s d q}-\frac{R_{s}}{\sigma L_{r}} \psi_{r d q}-j \omega_{s} \psi_{s d q}+v_{s d q} .
\end{aligned}
$$

The pole of the new equation is $s=-R_{s} / \sigma L_{s}-j \omega_{s}$. The damping coefficient is modified to $\alpha=-R_{s} / \sigma L_{s}$, and for the studied DFIG it becomes -25.6 which is quite greater than the previous damping coefficient. Therefore, in the proposed method not only the fault current distributed in more switches but the damping of the stator flux is also greatly increased.

\section{Simulation Results}

In this section the performance of a DFIG wind turbine is simulated under a severe fault condition. Simulations are carried out in PSIM environment to investigate the effects of switching. As was mentioned in Section 2 according to LVRT standard of Germany, wind turbines must remain connected to grid following occurrence of grid faults. Moreover, they must also inject reactive power to help the grid for voltage recovery. To simulate the fault condition, at $t=0.7 \mathrm{~s}$ the grid voltages are dropped to $0.2 \mathrm{pu}$ for $300 \mathrm{~ms}$ as shown in Figure 11. Figure 12 shows the rotor currents in this case without any protection. For such a severe voltage dip, the rotor currents are increased to $2.8 \mathrm{pu}$. In the absence of any type of protecting method, these high currents can damage the IGBT switches of the IMC. Figure 13 shows the rotor 


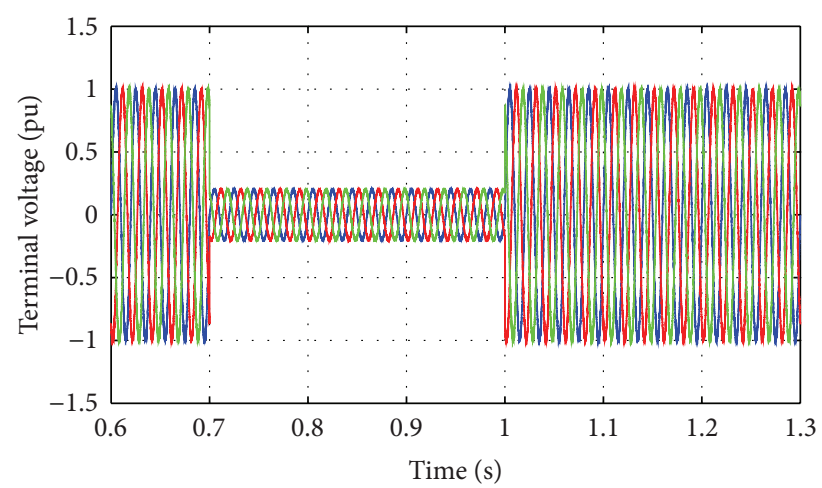

FIGURE 11: Grid voltages.

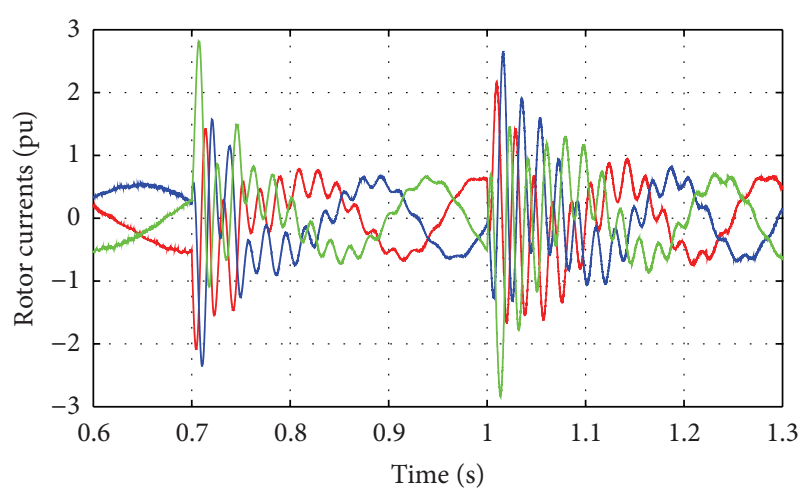

FIGURE 12: Rotor currents in fault condition, with the controller designed for normal operation.

currents when the proposed method is in operation. Short circuit activation signal is obtained from comparison of rotor currents with a threshold value. In this simulation the threshold value is set to $1.5 \mathrm{pu}$. When the rotor current is greater than the threshold value, the short circuit mode is activated. It means that all of the output stage switches are turned on. As was mentioned in the previous section, here the high fault currents of the rotor are distributed between output switches.

Figure 14 shows the currents flowing in IGBT switches in time interval from $t=0.72 \mathrm{~s}$ up to $t=0.77 \mathrm{~s}$ during activation of the short circuit mode. As shown in Figure 14, the currents through all switches are in the safe operating area (SOA). Furthermore, the duration of short circuit mode is less than $20 \mathrm{~ms}$, so there is a chance for reactive power injection as required by new LVRT standards. Short circuit mode activation signal is presented in Figure 13. It implies that the short circuit mode will be instantly activated if the rotor currents exceed the threshold value. The short circuit mode is active only for a short time, so, for most of the time during fault, the control system of DFIG is in operation to inject reactive power to grid. In order to meet the new LVRT standards, during fault the references of the active and reactive powers are set to $0.0 \mathrm{pu}$ and $1.0 \mathrm{pu}$, respectively. As can be seen from Figure 13, injection of 1.0 pu reactive current is realized in compliance with LVRT standard.

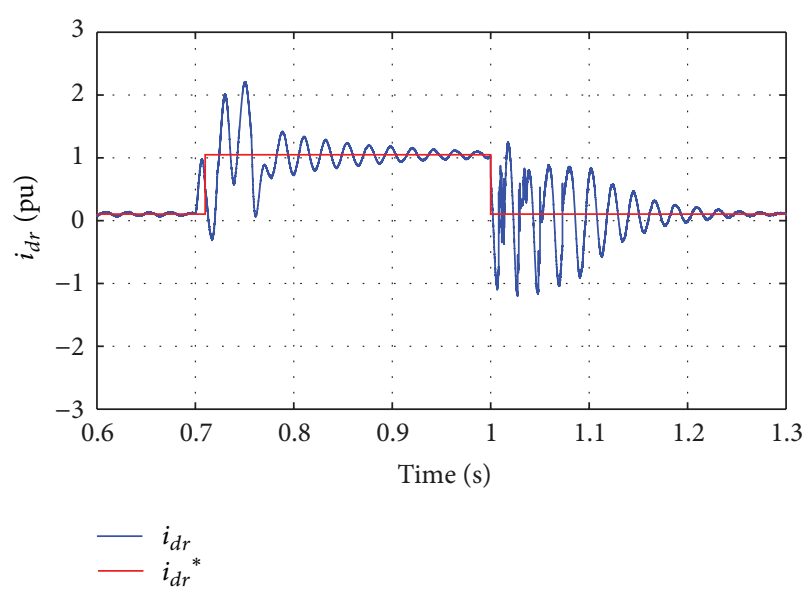

(a)

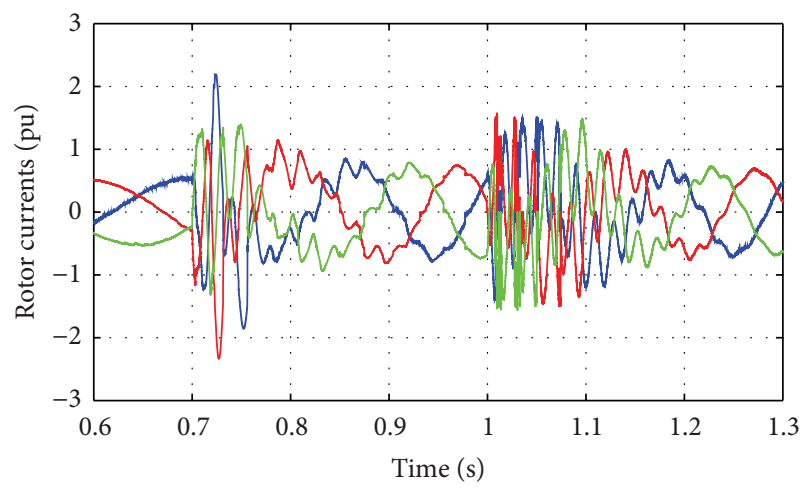

(b)

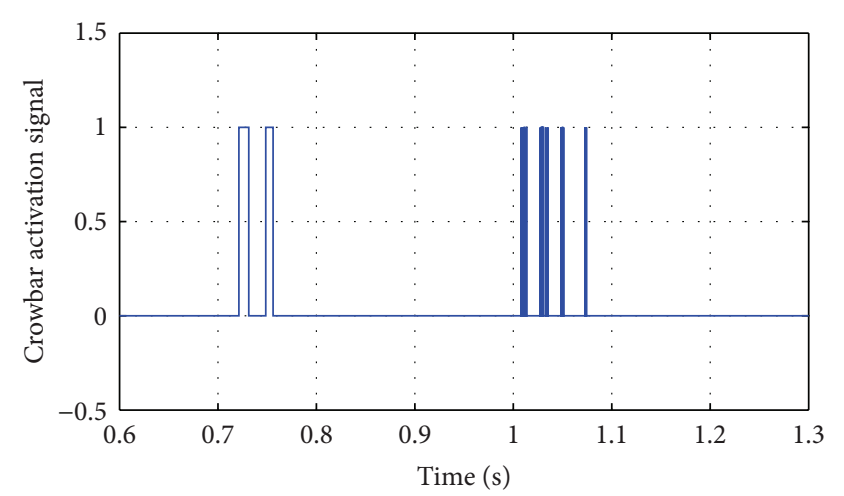

(c)

FIGURE 13: Rotor currents in fault condition, with the proposed method.

\section{Conclusion}

To enhance the LVRT capability of DFIG wind turbines based on indirect matrix converters (IMCs), in this paper a new crowbar system is proposed. This crowbar system is based on using the existing converter switches in short circuit mode to protect the IMC against large fault currents. Therefore, this method is interesting as it does not require any additional hardware. Even in severe fault conditions, the short circuit mode is active only for short time, so the control system can 


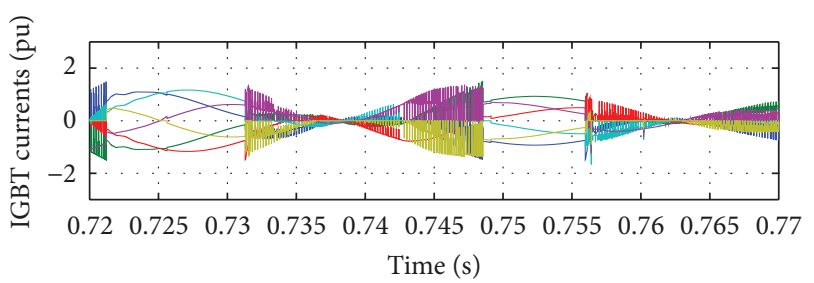

$\begin{array}{rr}I_{1} & -I_{4} \\ -I_{2} & -I_{5} \\ I_{3} & -I_{6}\end{array}$

(a)

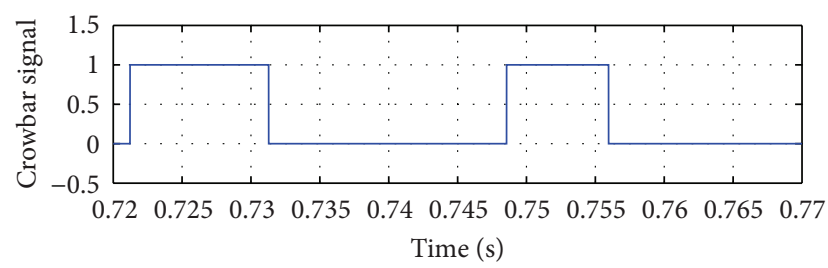

(b)

FIGURE 14: Rotor currents in fault condition, with the proposed method.

be in operation at most of the fault duration. Therefore, the reactive power injection is realized to help voltage recovery in order to satisfy the new LVRT standards. Simulation results confirm the efficiency of the proposed method.

\section{Appendix}

Parameters of the studied system are as follows.

Wind turbine:

$P_{\text {nom }}=1.5 \mathrm{MW}$,

Base wind speed $=12 \mathrm{~m} / \mathrm{s}$,

Moment of inertia: $1.2 \mathrm{Mkg} \cdot \mathrm{m}^{2}$.

Gearbox:

$$
n_{1} / n_{2}=1 / 100 \text {. }
$$

DFIG:

$$
\begin{aligned}
& P_{\text {nom }}=1.5 \mathrm{MW}, V_{\text {nom }}=690 \mathrm{~V}, \\
& f_{\text {nom }}=50 \mathrm{~Hz}, R_{s}=10.3 \mathrm{~m} \Omega, \\
& R_{r}=8.28 \mathrm{~m} \Omega, L_{l s}=0.2801 \mathrm{mH}, \\
& L_{l r}=0.1177 \mathrm{mH}, L_{m}=26.96 \mathrm{mH}, \\
& P=6, J=116 \mathrm{Kg} \cdot \mathrm{m}^{2} .
\end{aligned}
$$

\section{Conflict of Interests}

The authors declare that there is no conflict of interests regarding the publication of this paper.

\section{References}

[1] "World wind energy report 2010," Tech. Rep., World Wind Energy Association, Bonn, Germany, 2011, http://wwwwwind.ea.org.
[2] T. Friedli, J. W. Kolar, J. Rodriguez, and P. W. Wheeler, "Comparative evaluation of three-phase AC-AC matrix converter and voltage DC-link back-to-back converter systems," IEEE Transactions on Industrial Electronics, vol. 59, no. 12, pp. 44874510, 2012.

[3] L. Wei and T. A. Lipo, "A novel matrix converter topology with simple commutation," in Proceedings of the 36th IAS Annual Meeting of Industry Applications Conference, vol. 3, pp. 17491754, Chicago, Ill, USA, September 2001.

[4] G. Michalke, Variable speed wind turbines-modeling, control, and impact on power systems [Ph.D. thesis], Riso National Laboratory, Roskilde County, Denmark, 2008.

[5] Z. Lu, J. Xinmin, and Z. Liangyu, "A novel LVRT control strategy of DFIG based rotor active crowbar," in Proceedings of the AsiaPacific Power and Energy Engineering Conference (APPEEC '11), pp. 1-6, Wuhan, China, March 2011.

[6] W. Maoze, X. Wei, J. Hongjie, and Y. Xinghuo, "A novel method to optimize the active crowbar resistance for low voltage ride through operation of doubly-fed induction generator based on wind energy," in Proceedings of the IEEE International Symposium on Industrial Electronics, (ISIE '12), pp. 957-962, Hangzhou, China, May 2012.

[7] R. Lohde, S. Jensen, A. Knop, and F. W. Fuchs, "Analysis of three phase grid failure and doubly fed induction generator ride-through using crowbars," in Proceedings of the European Conference on Power Electronics and Applications, pp. 1-8, Aalborg, Denmark, September 2007.

[8] P. Ling, B. Francois, and L. Yongdong, "Improved crowbar control strategy of dfig based wind turbines for grid fault ridethrough," in Proceedings of the 24th Applied Power Electronics Conference and Exposition (APEC '09), pp. 1932-1938, Washington, DC, USA, February 2009.

[9] W. Zhang, P. Zhou, and Y. He, "Analysis of the by-pass resistance of an active crowbar for doubly-fed induction generator based wind turbines under grid faults," in Proceedings of the International Conference on Electrical Machines and Systems (ICEMS '08), pp. 2316-2321, Wuhan, China, October 2008.

[10] J. Yang, D. G. Dorrell, and J. E. Fletcher, "A new converter protection scheme for doubly-fed induction generators during disturbances," in Proceedings of the 34th Annual Conference of the IEEE Industrial Electronics Society, (IECON '08), pp. 21002105, Orlando, Fla, USA, November 2008.

[11] Z. Zhong, Y. Geng, and G. Hua, "Short circuit current analysis of DFIG-type WG with crowbar protection under grid faults," in Proceedings of the IEEE International Symposium on Industrial Electronics (ISIE '12), pp. 1072-1079, Hangzhou, China, May 2012.

[12] J. Zhai, B. Zhang, K. Wang, and W. Shao, “Three-phase symmetrical short circuit current characteristic analysis of doubly fed induction generator with crowbar protection," in Proceedings of the IEEE Innovative Smart Grid Technologies-Asia (ISGT Asia '12), pp. 1-5, Tianjin, China, May 2012.

[13] X. Shuai, Y. Geng, Z. Honglin, and G. Hua, "An LVRT control strategy based on flux linkage tracking for DFIG-based WECS," IEEE Transactions on Industrial Electronics, vol. 60, no. 7, pp. 2820-2832, 2013.

[14] M. Rahimi and M. Parniani, "Efficient control scheme of wind turbines with doubly fed induction generators for low-voltage ride-through capability enhancement," IET Renewable Power Generation, vol. 4, no. 3, pp. 242-252, 2010.

[15] I. Esandi, X. Juankorena, J. López, and L. Marroyo, "Alternative protection system for wind turbines with doubly fed 
induction generator," in Proceedings of the 2nd International Conference on Power Engineering, Energy and Electrical Drives (POWERENG '09), pp. 501-506, Lisbon, Portugal, March 2009.

[16] M. Rahimi and M. Parniani, "Grid-fault ride-through analysis and control of wind turbines with doubly fed induction generators," Electric Power Systems Research, vol. 80, no. 2, pp. 184-195, 2010.

[17] F. K. A. Lima, A. Luna, P. Rodriguez, E. H. Watanabe, and F. Blaabjerg, "Rotor voltage dynamics in the doubly fed induction generator during grid faults," IEEE Transactions on Power Electronics, vol. 25, no. 1, pp. 118-130, 2010.

[18] J. Liang, W. Qiao, and R. G. Harley, "Direct transient control of wind turbine driven DFIG for low voltage ride-through," in Proceedings of the IEEE Power Electronics and Machines in Wind Applications (PEMWA '09), pp. 1-7, Lincoln, Neb, USA, June 2009.

[19] X. Shuai, G. Hua, Z. Honglin, and Y. Geng, "Analysis of the control limit for rotor-side converter of doubly fed induction generator-based wind energy conversion system under various voltage dips," Renewable Power Generation, vol. 7, no. 1, pp. 7181, 2013.

[20] O. Gomis-Bellmunt, A. Junyent-Ferré, A. Sumper, and J. Bergas-Jané, "Ride-through control of a doubly fed induction generator under unbalanced voltage sags," IEEE Transactions on Energy Conversion, vol. 23, no. 4, pp. 1036-1045, 2008.

[21] Y. Zhou, P. Bauer, J. A. Ferreira, and J. Pierik, "Operation of gridconnected DFIG under unbalanced grid voltage condition," IEEE Transactions on Energy Conversion, vol. 24, no. 1, pp. 240246, 2009.

[22] D. Li and H. Zhang, "A combined protection and control strategy to enhance the LVRT capability of a wind turbine driven by DFIG," in Proceedings of the 2nd IEEE International Symposium on Power Electronics for Distributed Generation Systems, (PEDG '10), pp. 703-707, Hefei, China, June 2010.

[23] L. Qicheng and L. Yuping, "An integration of super capacitor storage research for improving low-voltage-ride-through in power grid with wind turbine," in Proceedings of the Asia-Pacific Power and Energy Engineering Conference (APPEEC '12), pp. 14, Shanghai, China, March 2012.

[24] W. Guo, L. Xiao, and S. Dai, "Enhancing low-voltage ridethrough capability and smoothing output power of DFIG with a superconducting fault-current limiter-magnetic energy storage system," IEEE Transactions on Energy Conversion, vol. 27, no. 2, pp. 277-295, 2012.

[25] A. Chakraborty, S. K. Musunuri, A. K. Srivastava, and A. K. Kondabathini, "Integrating statcom and battery energy storage system for power system transient stability: a review and application," Advances in Power Electronics, vol. 2012, Article ID 676010, 12 pages, 2012.

[26] K. Ibrahima and C. Zhao, "Modeling of wind energy conversion system using doubly fed induction generator equipped batteries energy storage system," in Proceedings of the 4th International Conference on Electric Utility Deregulation and Restructuring and Power Technologies, (DRPT '11), pp. 1780-1787, Weihai, China, July 2011.

[27] E. Reyes, R. Pena, R. Cardenas, P. Wheeler, J. Clare, and R. Blasco-Gimenez, "Application of indirect matrix converters to variable speed doubly fed induction generators," in Proceedings of the 39th IEEE Annual Power Electronics Specialists Conference (PESC '08), pp. 2698-2703, Rhodes, Greece, June 2008.

[28] J. Amini, R. Kazemzahed, and H. Madadi Kojabadi, "Performance enhancement of indirect matrix converter based variable speed Doubly-fed induction generator," in Proceedings of the 1st Power Electronic \& Drive Systems \& Technologies Conference (PEDSTC '10), pp. 450-455, Tehran, Iran, February 2010.

[29] E. Reyes, R. Pena, R. Cardenas, J. Clare, and P. Wheeler, "Control of a doubly-fed induction generator with an indirect matrix converter with changing DC voltage," in Proceedings of the IEEE International Symposium on Industrial Electronics (ISIE '10), pp. 1230-1235, Bari, Italy, July 2010.

[30] W. Deng, Z. Chen, L. Zhou, and Y. Yang, "Research on the performance of low voltage ride-through for doubly fed induction generator excited by two-stage matrix converter," in Proceedings of the IEEE 6th International Power Electronics and Motion Control Conference (IPEMC '09), pp. 638-643, Wuhan, China, May 2009.

[31] G. D. Marques and D. M. e Sousa, "A new sensorless MRAS based on active power calculations for rotor position estimation of a DFIG," Advances in Power Electronics, vol. 2011, Article ID 970364, 8 pages, 2011.

[32] J. D’Atre, A. Klodowski, A. Ritter et al., "System and method for power control in wind turbine," US Patent 0024059, 2007. 

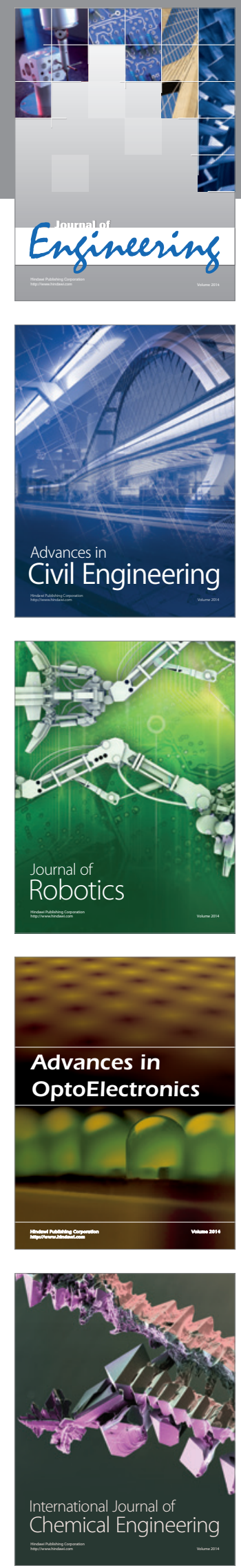

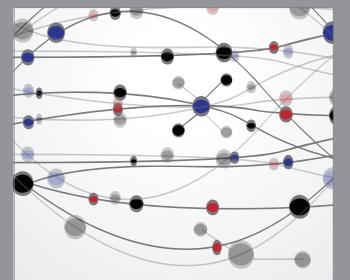

The Scientific World Journal
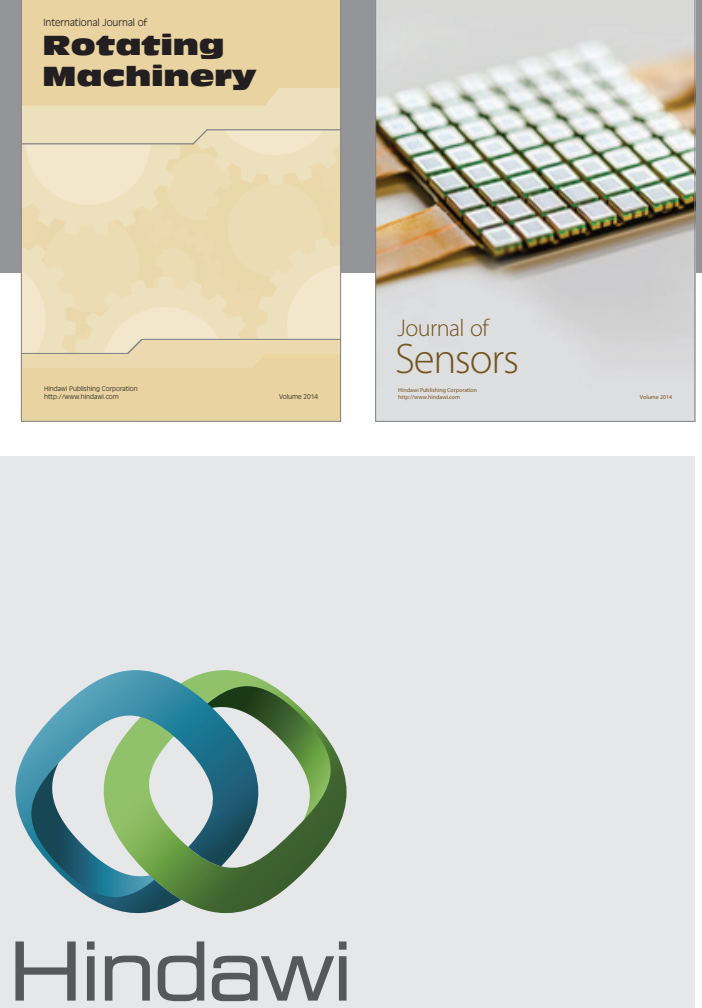

Submit your manuscripts at http://www.hindawi.com
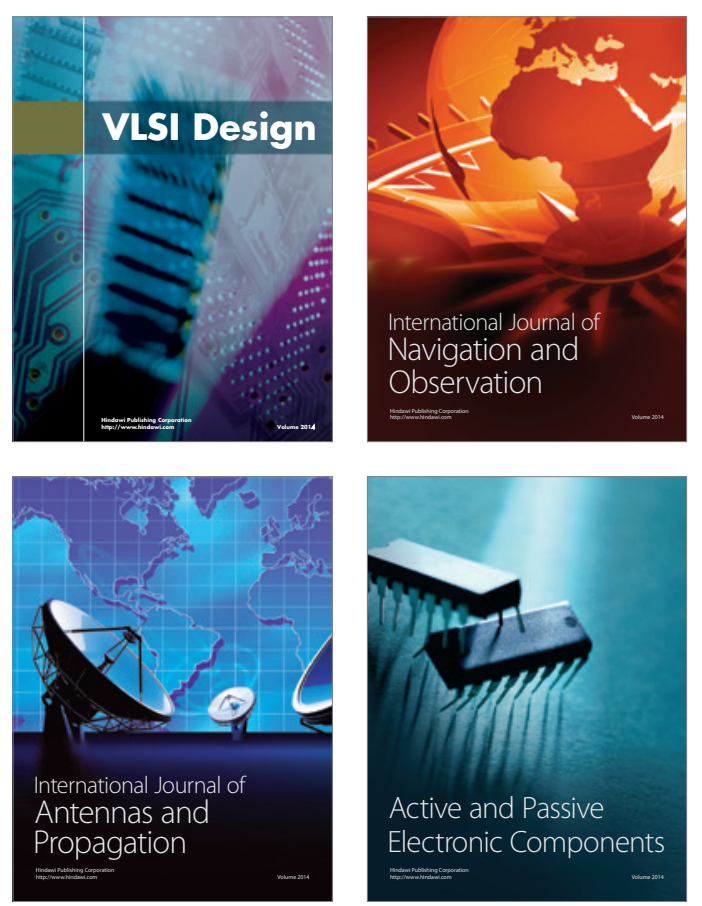
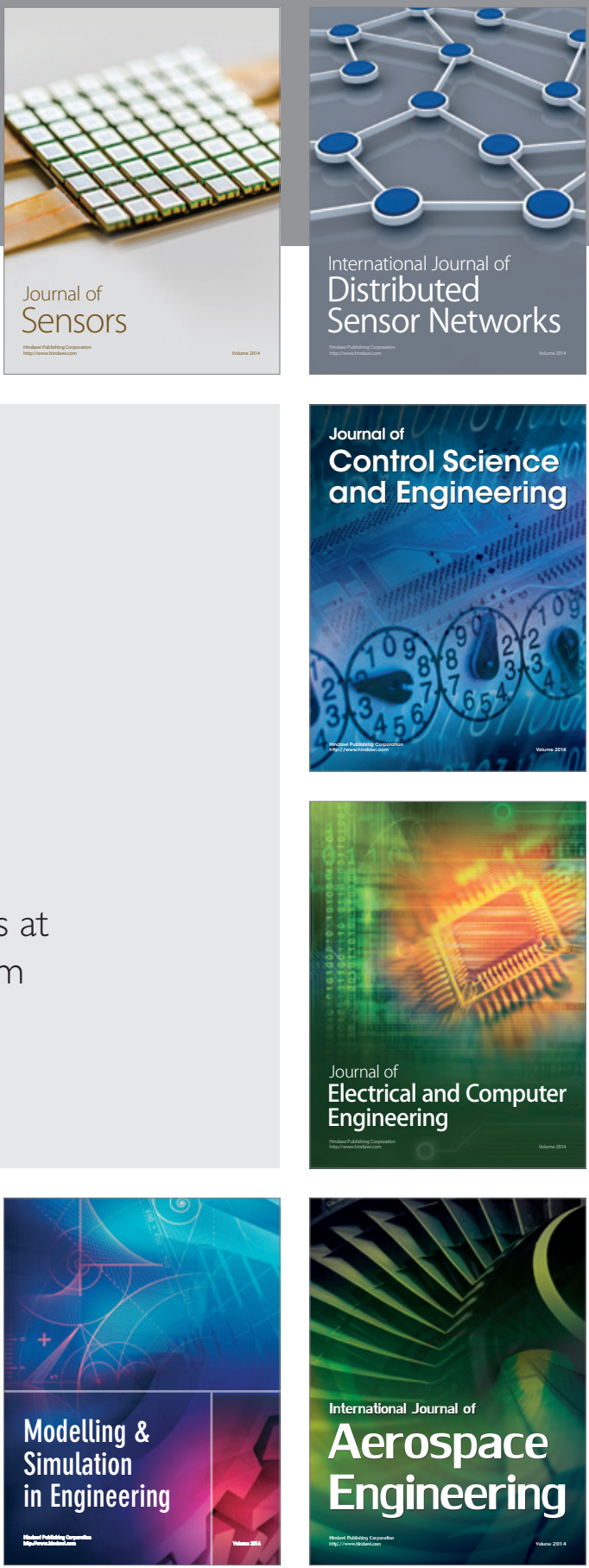

Journal of

Control Science

and Engineering
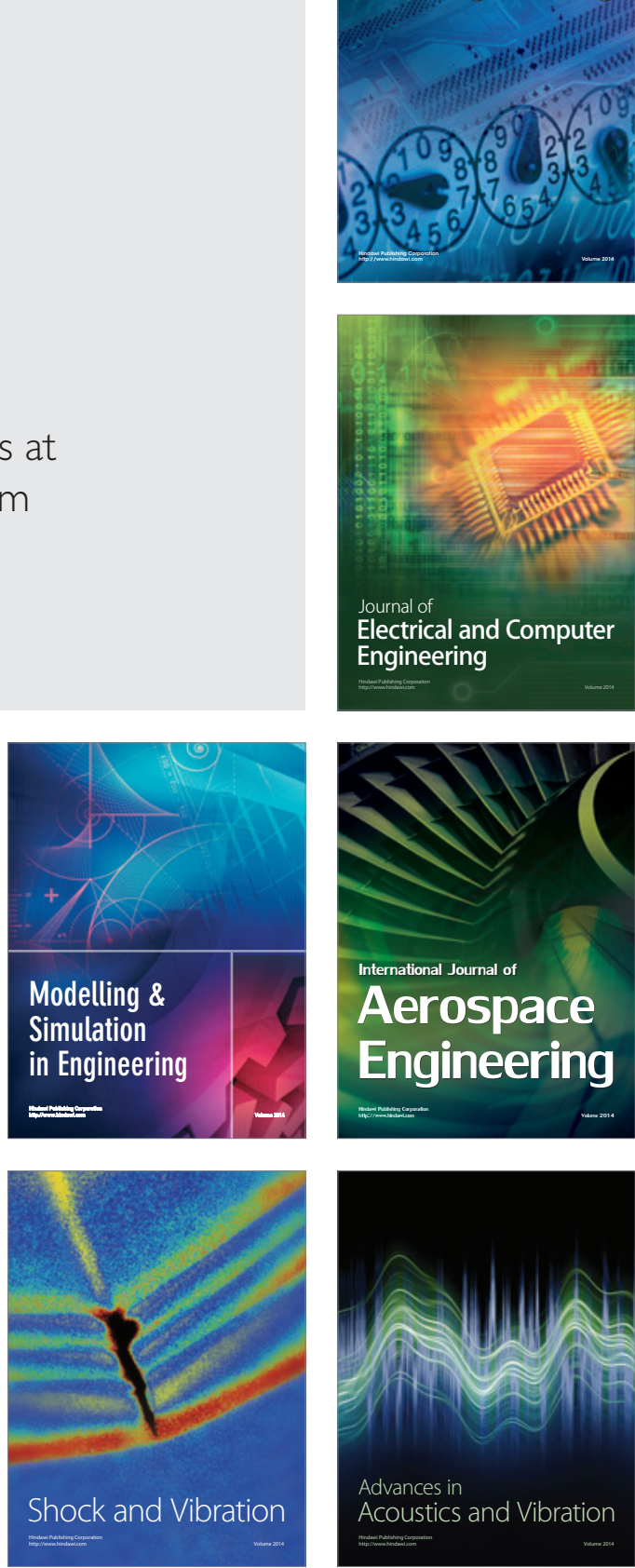